\title{
Visibility Analysis of Domestic Satellites on Proposed Ground Sites for Optical Surveillance
}

\author{
Jae-Hyuk Kim ${ }^{1,2 \dagger}$, Jung Hyun Jo ${ }^{1}$, Jin Choi ${ }^{1}$, Hong-Kyu Moon ${ }^{1}$, Young-Jun Choi ${ }^{1}$, \\ Hong-Suh Yim ${ }^{1}$, Jang-Hyun Park ${ }^{1}$, Eun-Seo Park ${ }^{1}$, and Jong-Uk Park ${ }^{1}$
}

${ }^{1}$ Korea Astronomy and Space Science Institute, Daejeon 305-348, Korea

${ }^{2}$ Department of Astronomy, Yonsei University, Seoul 120-749, Korea

The objectives of this study are to analyze the satellite visibility at the randomly established ground sites, to determine the five optimal ground sites to perform the optical surveillance and tracking of domestic satellites, and to verify the acquisition of the optical observation time sufficient to maintain the precise ephemeris at optimal ground sites that have been already determined. In order to accomplish these objectives, we analyzed the visibility for sun-synchronous orbit satellites, low earth orbit satellites, middle earth orbit satellites and domestic satellites as well as the continuous visibility along with the fictitious satellite ground track, and calculate the effective visibility. For the analysis, we carried out a series of repetitive process using the satellite tool kit simulation software developed by Analytical Graphics Incorporated. The lighting states of the penumbra and direct sun were set as the key constraints of the optical observation. The minimum of the observation satellite elevation angle was set to be 20 degree, whereas the maximum of the sun elevation angle was set to be -10 degree which is within the range of the nautical twilight. To select the candidates for the optimal optical observation, the entire globe was divided into 84 sectors in a constant interval, the visibility characteristics of the individual sectors were analyzed, and 17 ground sites were arbitrarily selected and analyzed further. Finally, five optimal ground sites (Khurel Togoot Observatory, Assy-Turgen Observatory, Tubitak National Observatory, Bisdee Tier Optical Astronomy Observatory, and South Africa Astronomical Observatory) were determined. The total observation period was decided as one year. To examine the seasonal variation, the simulation was performed for the period of three days or less with respect to spring, summer, fall and winter. In conclusion, we decided the optimal ground sites to perform the optical surveillance and tracking of domestic satellites and verified that optical observation time sufficient to maintain the precise ephemeris could be acquired at the determined observatories.

Keywords: optical surveillance, visibility analysis, dawn-dusk orbit, sun-synchronous orbit, ground track analysis, domestic satellites

\section{INTRODUCTION}

The attempt to determine satellite orbit and maintain the ephemeris through optical observation has been continuously made since Sputnik I was launched in 1957 (King-Hele 1983). The methods that are generally used for orbit observation such as satellite laser ranging (SLR), radar tracking and global positioning system (GPS) orbit tracking are superior to the orbit measurement by means of optical observation in terms of precision and accuracy. Among these orbit observation methods, SLR and GPS orbit tracking require the installation of a laser retro-reflector array (LRRA) or a GPS receiver (Pearlman et al. 2002). The orbit of the objects with which mutual communication is impossible, such as space debris or discarded satellites, cannot be determined by these two (c) This is an Open Access article distributed under the terms of the Creative Commons Attribution Non-Commercial License (http://creativecommons.org/licenses/by-nc/3.0/) which permits unrestricted non-commercial use, distribution, and reproduction in any medium, provided the original work is properly cited.
Received Aug 03, 2011 Revised Aug 25, 2011 Accepted Aug 31, 2011

${ }^{\dagger}$ Corresponding Author

E-mail: nasabolt@kasi.re.kr

Tel: +82-42-865-2185 Fax: +82-42-861-5610 
methods. However, the orbit determination by optical observation is not dependent on the transmission and reception of specific observation data. Refer to Kim et al. (1987) for detailed information on optical observation. If only the observable optical visibility and sufficient observation time are allowed, the satellite ephemeris can be maintained or improved by estimating the observation position on the celestial sphere in advance on the basis of the orbital elements of a given satellite. The important factors for this process are the effective range and possible frequency of the optical observation with reference to the ground. To explain the efficiency of optical observation to maintain satellite ephemeris, the optimal ground sites with the higher visibility should be determined first, and the effective visibility (EV) of each observatory should be analyzed (Jo 2011).

\section{VISIBILITY ANALYSIS OF SUN-SYNCHRONOUS ORBIT SATELLITES ON SECTORIZED FICTITOUS GROUND SITES}

Basically, for all the simulation process, the maximum of the sun elevation angle was set to be - 10 degree which is within the range of the nautical twilight. The lighting states of the penumbra and direct sun were set as the key constraints. The minimum of the observation satellite elevation angle was set to be 20 degree, which is the consideration of the light pollution and local sites. To analyze the visibility, 84 fictitious ground sites were set in a $30^{\circ}$ interval for the earth's latitude and longitude (Fig. 1). The entire simulation period was one year between Janu- ary and December, 2010. The subject satellite was Korea multi-purpose satellite-2 (KOMPSAT-2). Table 1 summarizes the specification of KOMPSAT-2. The orbit propagator used for the simulation was the simplified general perturbations propagator (SGP4) ${ }^{1}$ that receives the twoline elements (TLE) provided by Analytical Graphics Incorporated (AGI) as the input orbital elements to predict the orbit.

KOMPSAT-2, a domestic sun-synchronous orbit (SSO) satellite, was observationally visible only in the high latitude region (north latitude 34 degrees or higher or south latitude 30 degrees or higher) as shown in Fig. 2. For about 300 astronomical observatories including ground-based astronomical facilities and overseas observatories in the

Table 1. KOMPSAT-2 satellite and orbit specification.*

\begin{tabular}{ll}
\hline Satellite information & \\
\hline Launch date & 20060728 \\
Projectile & Rokot rocket \\
Launch site & Plesetsk, Russia \\
Mass & $800 \mathrm{~kg}$ \\
Diameter & $200 \mathrm{~cm}$ \\
Height & $280 \mathrm{~cm}$ \\
\hline Orbital elements & \\
\hline Perigee & $656.2999877929688 \mathrm{~km}$ \\
Apogee & $680.9000244140625 \mathrm{~km}$ \\
Orbital period & $98.5999984741211 \mathrm{~min}$ \\
Inclination & $98.0999984741211 \mathrm{deg}$ \\
Eccentricity & 0.0017455226043239236 \\
Orbit & $\mathrm{SSO}$ \\
\hline
\end{tabular}

KOMPSAT-2: Korea multi-purpose satellite-2, SSO: sun-synchronous orbit. "http://en.wikipedia.org/wiki/Arirang-2 [cited 2011 Feb 4]

${ }^{1}$ http://www.stk.com/resources/help/online/stk/source/stk/vehsat_orbitprop_ choose.htm [cited 2011 Feb 2]

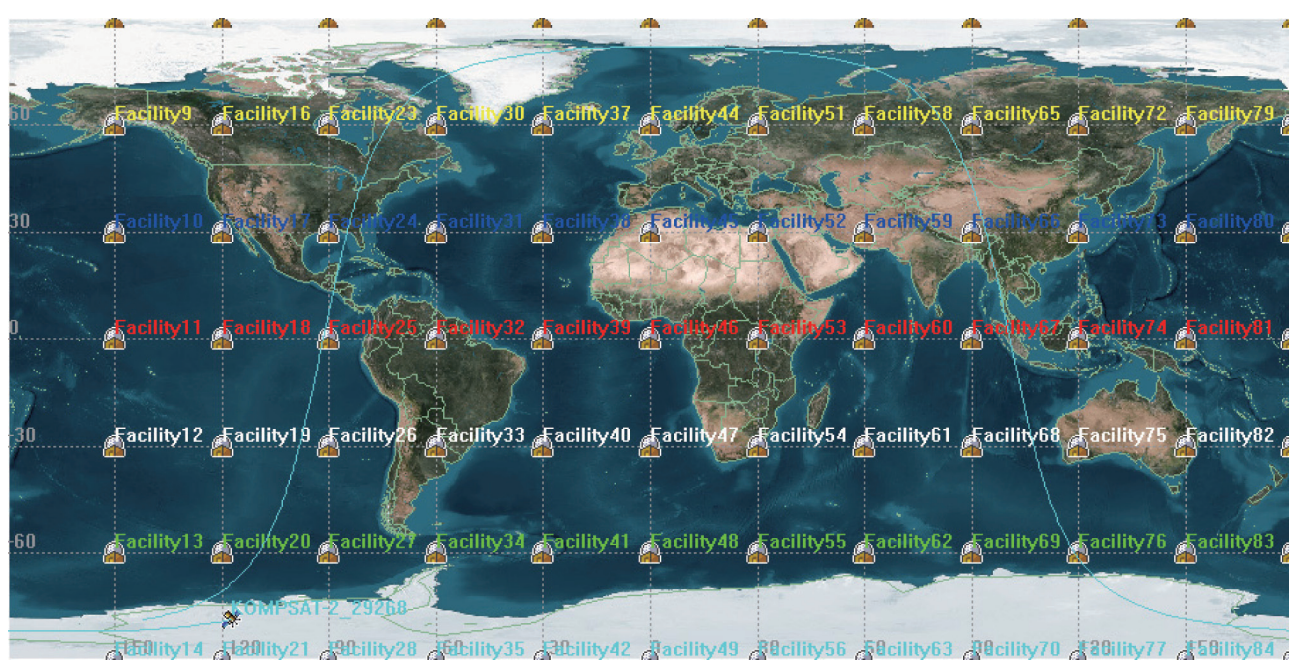

Fig. 1. Eighty-four sectorized fictitious ground sites are positioned every $30 \mathrm{deg}\left(30^{\circ} \times 30^{\circ}\right)$, and the text color means same latitude mark, the ground track displayed in the figure is by Korea multi-purpose satellite-2 (KOMPSAT-2). 
list of astronomical observatories ${ }^{2}$, we checked out the weather conditions, number of clearly sky days, and provision of the communication and technological support. Excluding the candidate observatories in the countries that are difficult to approach because of international political reasons, 17 candidate observatories were set as in Table 2 . The visibility for the SSO satellites that are generally known at the determined observatories was verified as shown in Table 3. The GeoEye satellite (Fig. 3) had the most narrow visibility range which was north latitude 35 degrees or higher or south latitude 40 degrees or higher, whereas the national oceanic and atmospheric adminis-

${ }^{2} \mathrm{http}$ //en.wikipedia.org/wiki/List_of_astronomical_observatories [cited 2011 Feb 7] tration-18 (NOAA-18) satellite (Fig. 4) had the widest visibility range which was north latitude 25 degrees or higher or south latitude 30 degrees or higher.

\section{VISIBILITY ANALYSIS OF LOW EARTH ORBIT AND MIDDLE EARTH ORBIT SATELLITES ON PROPOSED 17 GROUND SITES}

Before analyzing the visibility of the low earth orbit (LEO) satellites and middle earth orbit (MEO) satellites, we verified if it was possible to categorize currently operating satellites according to orbital elements, and if the categorized groups had the visibility characteristics.

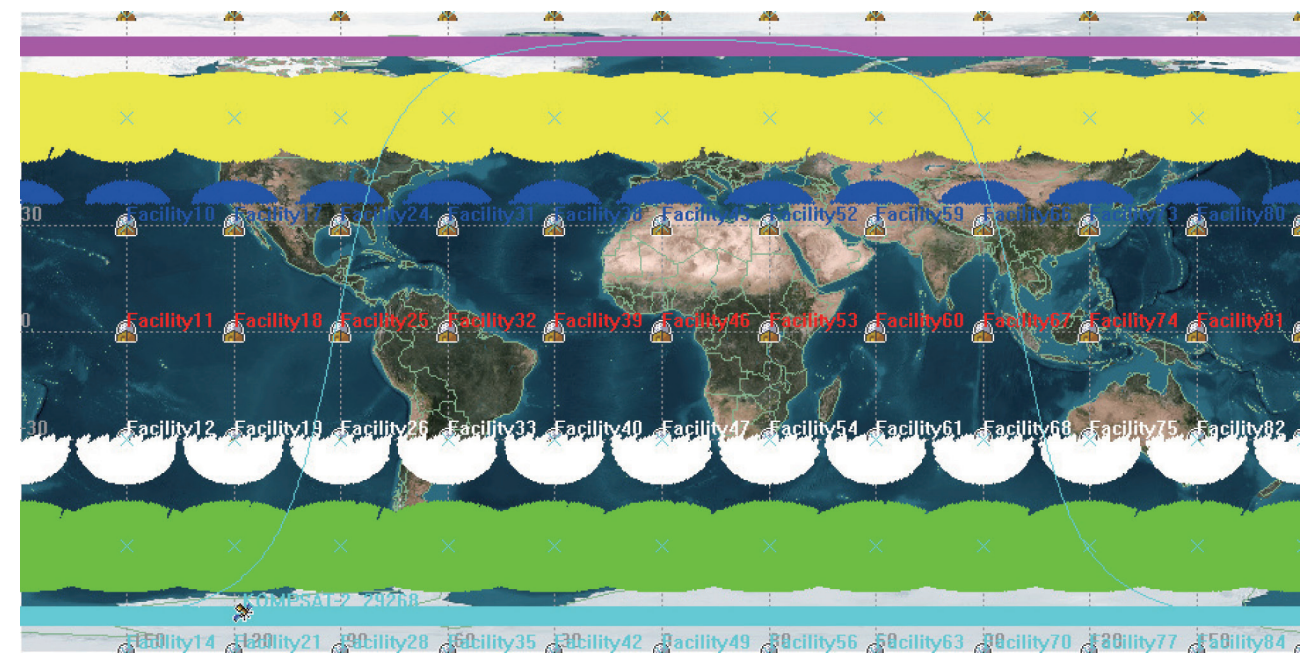

Fig. 2. Visibility of KOMPSAT-2 on 84 sectorized fictitious ground sites is drawn in topocentric horizon, and the results of same latitude are represented same colors (Kim 2011a).

Table 2. Characteristics of proposed 17 ground sites (Moon 2011).

\begin{tabular}{|c|c|c|c|c|}
\hline Proposed ground sites & Latitude (deg) & Longitude (deg) & Elevation (m) & Main telescope \\
\hline Khurel Togoot Observatory & 47.865 & 107.0536111 & 1,620 & $0.4 \mathrm{~m}$ \\
\hline Indian Astronomical Observatory & 32.77944444 & 78.96416667 & 4,500 & $2 \mathrm{~m}$ \\
\hline Assy-Turgen Observatory & 43.22444444 & 77.87138889 & 2,665 & $1 \mathrm{~m} \mathrm{RC}$ \\
\hline Tien-Shan Observatory & 43.95 & 76.95 & 2,800 & $1 \mathrm{~m} \mathrm{RC}$ \\
\hline Pamir High-Mountain Observatory & 38 & 74 & 4,350 & $0.7 \mathrm{~m} \mathrm{RC}$ \\
\hline Sanglokh Observatory & 38.2 & 69 & 2,300 & $1 \mathrm{~m} \mathrm{RC}$ \\
\hline Mount Dushak-Erekdag Observatory & 37.95583333 & 57.90583333 & 2,020 & $1 \mathrm{~m}$ Wide-field \\
\hline Maidanak Observatory & 38.6725 & 66.90083333 & 2,000 & $1.5 \mathrm{~m}$ \\
\hline Roque de Los Muchachos Observatory & 28.76666667 & -17.88333333 & 2,396 & $11.35 \mathrm{~m} \mathrm{GTC}$ \\
\hline Skinakas Observatory & 35.21194444 & 24.89916667 & 1,750 & $1.3 \mathrm{~m} \mathrm{RC}$ \\
\hline Tubitak National Observatory & 36.82416667 & 30.33555556 & 2,500 & $1.5 \mathrm{~m}$ \\
\hline Observatorio Astronómico Nacional en San Pedro Mártir & 31.04444444 & -115.4666667 & 2,800 & $2.1 \mathrm{~m}$ \\
\hline Bisdee Tier Optical Astronomy Observatory & -42.42583333 & 147.2886111 & 646 & $1.3 \mathrm{~m}$ \\
\hline Siding Spring Observatory & -31.27333333 & 149.0644444 & 1,165 & $3.9 \mathrm{~m} \mathrm{AAT}$ \\
\hline Vintage Lane Observatory & -41.49333333 & 173.8391667 & 37.50 & $0.6 \mathrm{~m} \mathrm{RC}$ \\
\hline South African Astronomical Observatory & -32.378 & 20.8105 & 1,759 & 10 m SALT \\
\hline Las Campanas Observatory & -29.015 & -70.77277778 & 2,380 & $6.5 \mathrm{~m} \mathrm{MT}$ \\
\hline
\end{tabular}

Las Campanas Observatory

RC: Ritchey-Chretien, GTC: gran telesc

telescope, MT: Magellan telescope. 


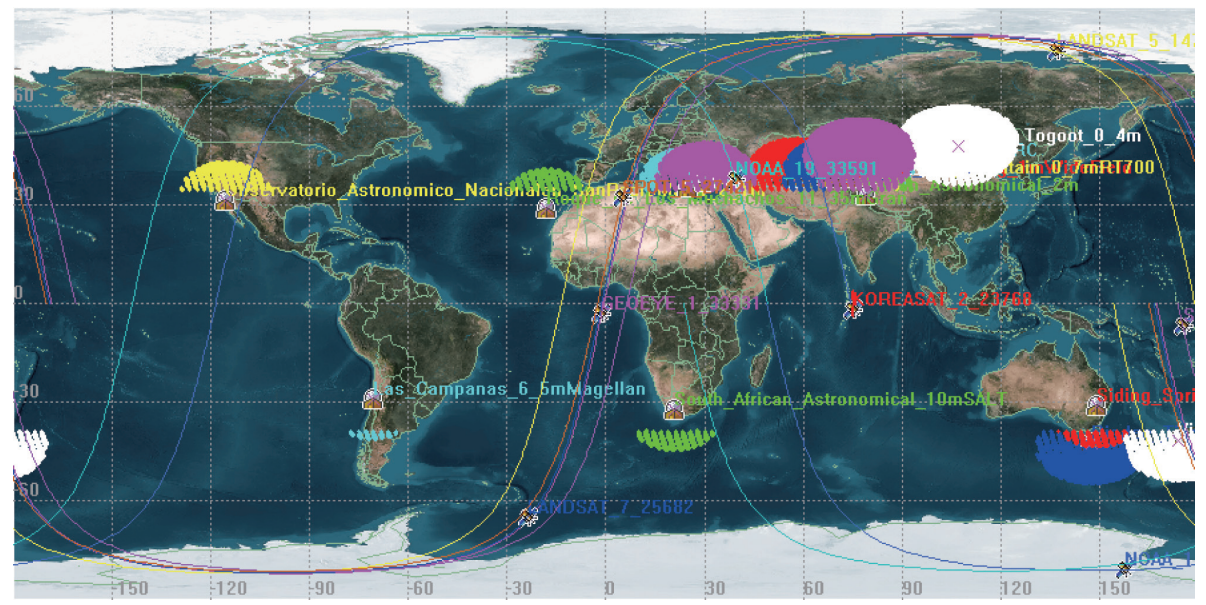

Fig. 3. Visibility of GeoEye on proposed 17 ground sites is drawn in topocentric horizon, and the different color distinguish between sites. The color was assigned randomly.

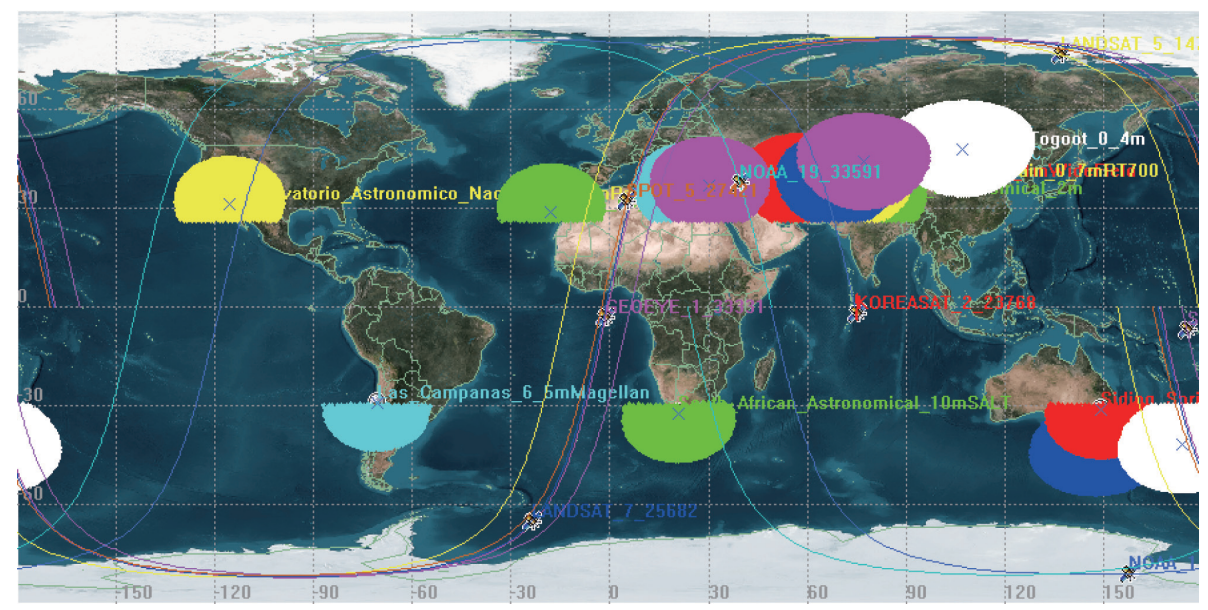

Fig. 4. Visibility of national oceanic and atmospheric administration-18 (NOAA-18) on proposed 17 ground sites is drawn in topocentric horizon, and the different color distinguish between sites. The color was assigned randomly.

Table 3. The specifications of several sun-synchronous orbit satellites.*

\begin{tabular}{|c|c|c|c|c|c|c|c|}
\hline Satellite & Launch date & Vehicle & Management & Orbit & Altitude(km) & Inclination (deg) & Goal \\
\hline LANDSAT 5 & 1984.3.1 & $\begin{array}{l}\text { Delta } \\
3920\end{array}$ & NASA & $\begin{array}{l}\text { Sun-synchronous, } \\
\text { near-polar orbit }\end{array}$ & 705 & 98.2 & $\begin{array}{l}\text { Global archive of } \\
\text { satellite photos }\end{array}$ \\
\hline LANDSAT 7 & 1999.4.15 & $\begin{array}{l}\text { Delta II } \\
7920\end{array}$ & NASA & $\begin{array}{l}\text { Sun-synchronous, } \\
\text { near-polar }\end{array}$ & 705 & 98.2 & $\begin{array}{l}\text { Refresh the global } \\
\text { archive of satellite } \\
\text { photos, providing } \\
\text { up-to-date and } \\
\text { cloud-free images }\end{array}$ \\
\hline NOAA 18 & 2005.5 .20 & $\begin{array}{l}\text { Delta II } \\
7320\end{array}$ & NASA & Sun-synchronous & 854 & 98.74 & $\begin{array}{l}\text { Weather and climate } \\
\text { predictions }\end{array}$ \\
\hline NOAA 19 & 2009.2 .6 & $\begin{array}{l}\text { Delta II } \\
7320\end{array}$ & NASA & Sun-synchronous & 870 & 98.7 & $\begin{array}{l}\text { Weather and climate } \\
\text { predictions }\end{array}$ \\
\hline SPOT4 & 1998.3.24 & $\begin{array}{l}\text { Ariane } \mathrm{V} \\
107\end{array}$ & CNES & Sun-synchronous & 802 & 98.7 & $\begin{array}{l}\text { Remote sensing, Earth } \\
\text { resources satellite }\end{array}$ \\
\hline SPOT5 & 2002.5 .3 & Ariane 4 & CNES & Sun-synchronous & 822 & 98.7 & $\begin{array}{l}\text { Remote sensing, Earth } \\
\text { resources satellite }\end{array}$ \\
\hline GeoEye & 2008.9.6 & Delta II & OSC & Sun-synchronous & 684 & 98 & $\begin{array}{l}\text { Earth observation } \\
\text { satellite }\end{array}$ \\
\hline
\end{tabular}

NASA: national aeronautics and space administration, CNES: centre national d'etudes spatiales, OSC: orbital sciences corporation, LANDSAT: land satellite (originally named earth resources technology satellite), NOAA: national oceanic and atmospheric administration, SPOT: système probatoire d'observation de la terre "http://www.n2yo.com/database/ [cited 2011 Mar 24] 


\subsection{Categorization of Satellites According to Orbital Elements}

We chose 5867 satellites and unidentified flying objects for which TLE were available in the collected data. The horizontal axis in Fig. 5 represents the satellites arranged in order with respect to the orbital elements, while the vertical axis the orbital elements corresponding to the individual satellites. We arranged the satellites according to the orbital eccentricity, orbital inclination, ascending node, perigean declination, and the mean anomaly, and searched the orbital elements with which categorization might be performed. The result showed that the satellites were concentrated within a specific range of orbital
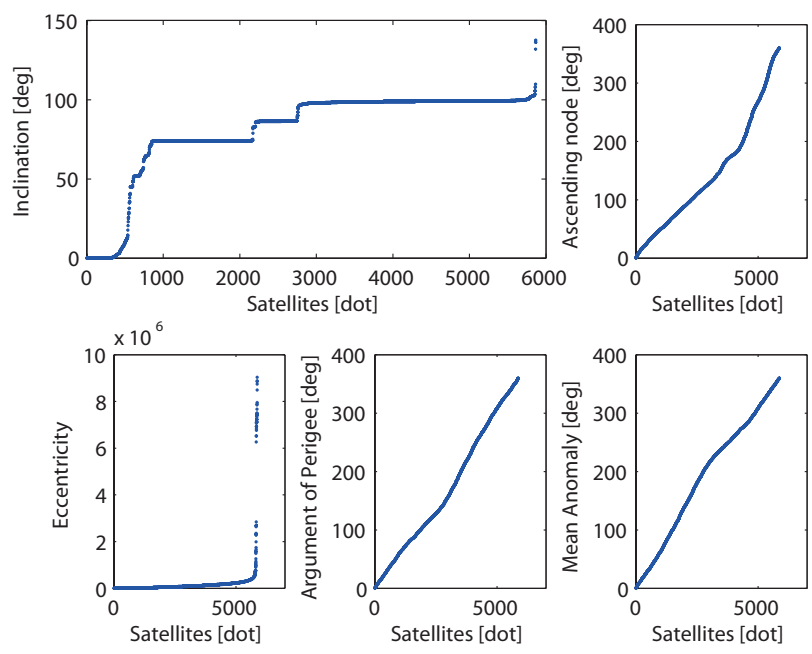

Fig. 5. Distribution of the orbital elements of 5867 satellites (Kim 2011b). inclination (70-76, 80-91, and 94-100 degree) as shown in Fig. 5.

\subsection{Visibility Analysis of the LEO and MEO Satellites}

To verify orbital inclination can be a characteristic that may affect the visibility, we categorized the LEO and MEO satellites according to the orbital inclination and analyzed the visibility for the 17 optimal ground site candidates. The total simulation period was one year between January and December, 2010. The specifications of the subject satellites are summarized in Table 4 . The SGP4 orbital propagator was used for each satellite.

\subsection{The Visibility Analysis Result}

The visibility and the observation frequency of the 23 LEO and MEO satellites were independent on the orbital elements, and the difference was less than $1 \sigma$ among the optimal ground site candidates. The visibility difference was negligible between the orbital communications flight model-2 (ORBCOMM FM-2) satellite (Fig. 6) having the smallest orbital inclination and NOAA-16 (Fig. 7) having the greatest orbital inclination. None of the other satellites was affected by the orbital inclination. Thus, it is difficult to categorize the satellites in view of the orbit and determine the optimal ground site with reference to a general standard. Simulation needs to be performed for domestic satellites and the satellites that are to be launched in the country according to the characteristics and properties of the mission which is the optical surveillance and tracking of the domestic satellites.

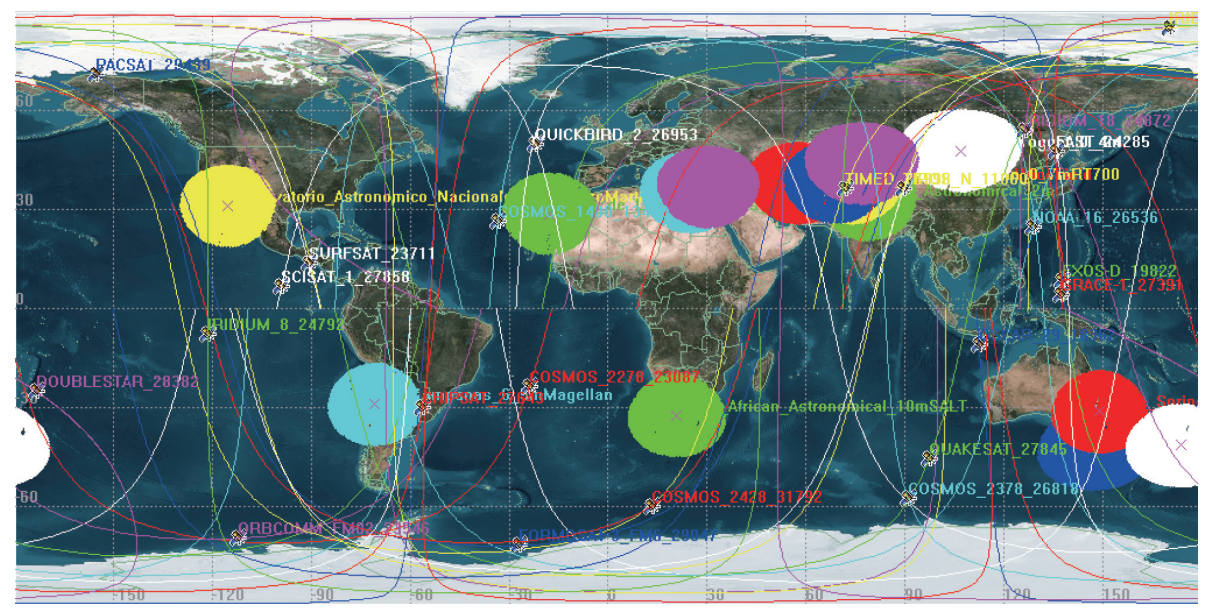

Fig. 6. Visibility of orbital communications flight model-2 (ORBCOMM FM-2) on proposed 17 ground sites is drawn in topocentric horizon, and the different color distinguish between sites. 


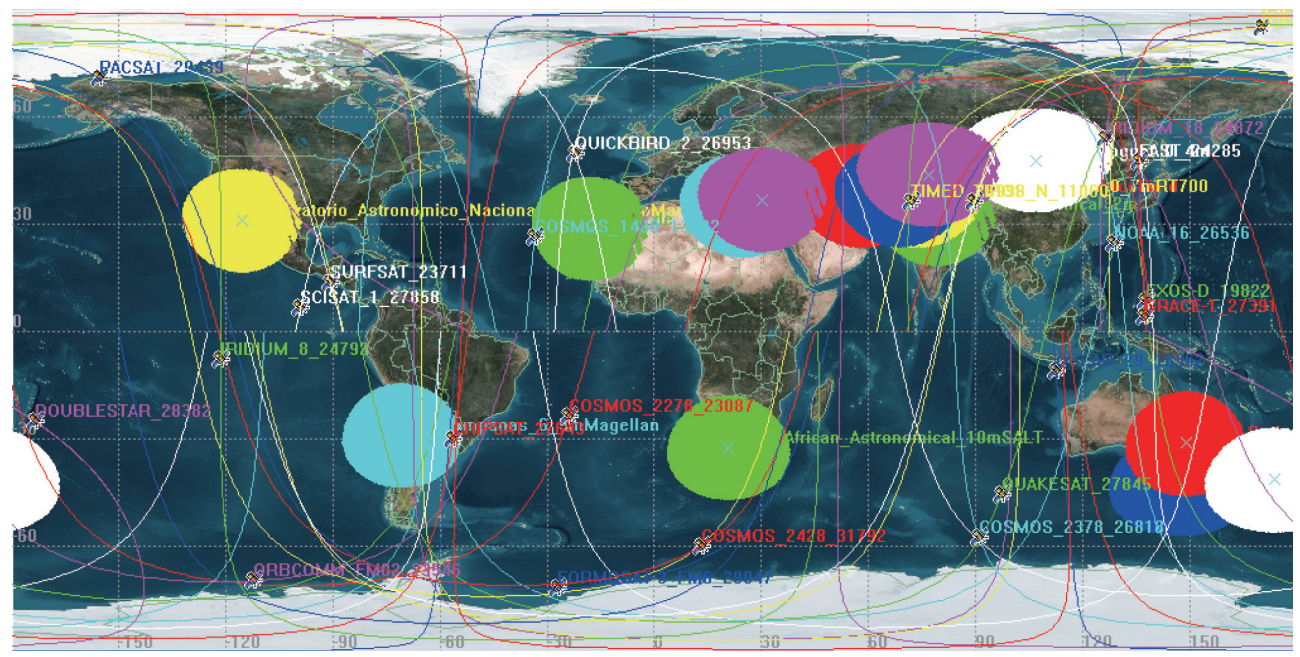

Fig. 7. Visibility of national oceanic and atmospheric administration-16 (NOAA-16) on proposed 17 ground sites is drawn in topocentric horizon, and the different color distinguish between sites.

Table 4. 23 satellites representing typical LEO and MEO orbital characteristics*

\begin{tabular}{|c|c|c|c|c|c|c|c|c|}
\hline Inclination & NORAD ID & Satellite & Perigee (km) & Apogee (km) & Inclination (deg) & Altitude (km) & Period (min) & Information \\
\hline \multirow[t]{7}{*}{$\overline{70 \sim 76}$} & 23546 & ORBCOMM FM 2 & 689.9 & 700.1 & 69.9772 & 674.99 & 98.5 & \\
\hline & 31792 & COSMOS 2428 & 851.1 & 865.8 & 70.9861 & 838.14692 & 102 & \\
\hline & 23087 & COSMOS 2278 & 849.4 & 861 & 71.0544 & 834.86388 & 101.9 & \\
\hline & 29047 & FORMOSAT 3A & 770.6 & 846.1 & 71.9783 & 788.12123 & 100.9 & \\
\hline & 27858 & SCISAT 1 & 646.5 & 658.5 & 73.9317 & 632.62571 & 97.6 & \\
\hline & 26998 & TIMED & 621.8 & 624.2 & 74.0713 & 603.14358 & 97 & \\
\hline & 19822 & EXOS D (AKEBONO) & 272.1 & 5023.4 & 75.081 & 2625.0777 & 142.1 & $\begin{array}{l}\text { Investigate } \\
\text { the particle } \\
\text { acceleration } \\
\text { regions } \\
\text { above the } \\
\text { auroral } \\
\text { region }\end{array}$ \\
\hline \multirow[t]{9}{*}{$80 \sim 91$} & 13402 & COSMOS 1400 & 476.8 & 486.7 & 81.1303 & 462.20501 & 94.1 & \\
\hline & 24285 & FAST & 355.9 & 3695.3 & 82.9676 & 2003.2207 & 127.6 & $\begin{array}{l}\text { Designed to } \\
\text { study Earth's } \\
\text { aurora. }\end{array}$ \\
\hline & 26818 & COSMOS 2378 & 968.7 & 1017.8 & 82.9228 & 972.73001 & 104.8 & \\
\hline & 24872 & IRIDIUM 18 & 783.2 & 786.4 & 86.391 & 764.63005 & 100.4 & \\
\hline & 25039 & IRIDIUM 43 & 783.2 & 786.3 & 86.3926 & 764.62995 & 100.4 & \\
\hline & 24792 & IRIDIUM 8 & 783.2 & 786.4 & 86.3939 & 764.64807 & 100.4 & \\
\hline & 27391 & GRACE 1 & 458.5 & 475.7 & 89.0072 & 447.55374 & 93.8 & \\
\hline & 28382 & DOUBLESTAR & 242.4 & 38155.5 & 88.4161 & 19150.291 & 678.2 & $\begin{array}{l}\text { Similar to the } \\
\text { equatorial } \\
\text { orbiter }\end{array}$ \\
\hline & 18362 & OSCAR 29 & 1023.6 & 1181.5 & 90.3507 & 1081.7974 & 107.2 & $\begin{array}{l}\text { Navy } \\
\text { Navigation } \\
\text { Satellite }\end{array}$ \\
\hline \multirow[t]{7}{*}{$94 \sim 100$} & 27643 & CHIPSAT & 571.3 & 591 & 94.0136 & 561.36748 & 96.1 & \\
\hline & 26953 & QUICKBIRD 2 & 452.7 & 454.8 & 97.0951 & 434.23216 & 93.5 & \\
\hline & 20439 & PACSAT (OSCAR 16) & 784.8 & 800.3 & 98.3672 & 772.36822 & 100.6 & \\
\hline & 27845 & QUAKESAT & 824.9 & 837.2 & 98.7168 & 810.79274 & 101.4 & \\
\hline & 11060 & TIROS N & 832.5 & 849.1 & 99.0041 & 820.56773 & 101.6 & \\
\hline & 26536 & NOAA 16 & 849.9 & 865.4 & 99.1535 & 837.34856 & 101.9 & \\
\hline & 23711 & SURFSAT & 940.8 & 1499.9 & 100.3324 & 1199.3774 & 109.7 & \\
\hline
\end{tabular}

LEO: low earth orbit, MEO: middle earth orbit, NORAD: north American aerospace defense command, ORBCOMM FM-2: orbital communications flight model-2, FORMOSAT-3A(ROCSat-3A): republic of China satellite-3A, SCISAT-1: science satellite-1, TIMED: thermosphere ionosphere mesosphere energetic and dynamics, EXOS D(AKEBONO): exospheric satellite D, FAST: fast, affordable, science and technology satellite, GRACE-1: grace recovery and climate experiment-1, OSCAR: orbiting satellite carrying amateur radio, CHIPSAT: cosmic hot interstellar plasma spectrometer satellite, TIROS N: television infrared observation satellite N, NOAA: national oceanic and atmospheric administration, SURFSAT: summer undergraduate research fellowship satellite.

"http://www.n2yo.com/database/ [cited 2011 Mar 28] 


\section{VISIBILITY ANALYSIS OF DOMESTIC SATEL- LITES ON PROPOSED 17 GROUND SITES}

The visibility of ten domestic satellites was analyzed for the 17 optimal ground site candidates. The total simulation period was one year between January and December, 2011, and the simulation was performed for one extra day for each equinox and solstice (the spring equinox, summer solstice, autumnal equinox and winter solstice). The specifications of the subject domestic satellites are shown in Table 5. To make the final determination of the five optimal ground sites, we fixed ground sites that solely had a local superiority to the surroundings (Las Campanas Observatory, South African Astronomical Observatory, and Observatorio Astronómico Nacional en San Pedro Mártir), made 33 combinations with the observatories concentrated on the southern hemisphere (Bisdee Tier Optical Astronomy Observatory, Siding Spring Observatory, and Vintage Lane Observatory), and compared them as shown in Table 6. The orbits of the domestic satellites

Table 5. Specification of the launched domestic satellites.*

\begin{tabular}{|c|c|c|c|c|c|c|c|}
\hline Satellite & NORAD ID & Launch date & $\begin{array}{c}\text { Perigee } \\
(\mathbf{k m})\end{array}$ & $\begin{array}{l}\text { Apogee } \\
(\mathrm{km})\end{array}$ & $\begin{array}{c}\text { Inclination } \\
\text { (deg) }\end{array}$ & $\begin{array}{c}\text { Period } \\
(\mathrm{min})\end{array}$ & $\begin{array}{c}\text { Semi-major axis } \\
(\mathbf{k m})\end{array}$ \\
\hline COMS-1 & 36744 & 2010.06 .26 & $35,787.2$ & $35,798.8$ & 0.0 & $1,436.1$ & $42,164.0$ \\
\hline KITSAT-1 & 22077 & 1992.08 .10 & $1,313.9$ & $1,331.6$ & 66.1 & 111.9 & $7,693.8$ \\
\hline KITSAT-2 & 22828 & 1993.09.26 & 791.6 & 806.9 & 98.5 & 100.7 & $7,170.3$ \\
\hline KITSAT-3 & 25756 & 1999.05.26 & 714.3 & 734.2 & 98.6 & 99.1 & $7,095.2$ \\
\hline KOMPSAT-1 & 26032 & 1999.12.21 & 678.1 & 685.0 & 97.8 & 98.2 & $7,052.6$ \\
\hline KOMPSAT-2 & 29268 & 2006.07 .28 & 685.7 & 706.2 & 98.3 & 98.5 & $7,066.9$ \\
\hline KOREASAT-1 & 23639 & 1995.08.05 & $35,939.2$ & $35,985.2$ & 10.4 & $1,444.7$ & $42,333.2$ \\
\hline KOREASAT-2 & 23768 & 1996.01.14 & $35,787.9$ & $35,799.1$ & 3.9 & $1,436.1$ & $42,164.5$ \\
\hline KOREASAT-3 & 25894 & 1999.09.04 & $35,791.1$ & $35,795.1$ & 0.0 & $1,436.1$ & $42,164.1$ \\
\hline KOREASAT-5 & 29349 & 2006.08.22 & $35,785.5$ & $35,803.3$ & 0.0 & $1,436.1$ & $42,165.4$ \\
\hline STSAT- 1 & 27945 & 2003.09.27 & 681.3 & 698.1 & 97.8 & 98.4 & $7,060.7$ \\
\hline
\end{tabular}

NORAD: north American aerospace defense command, COMS-1: communication, ocean and meteorological satellite-1, KITSAT: Korean institute of technology satellite, KOMPSAT: Korea multi-purpose satellite, STSAT-1: science and technology satellite-1.

*http://www.n2yo.com/database/ [cited 2011 Mar 29]

Table 6. The number of 33 cases for the combination of 5 ground sites for best visibility.

\begin{tabular}{|c|c|c|c|c|c|}
\hline Case & Standard ground sites & Candidate ground sites & \multicolumn{3}{|c|}{ Fixed ground sites } \\
\hline 1 & Bisdee Tier Optical Astronomy Observatory & Khurel Togoot Observatory & \multirow{33}{*}{ 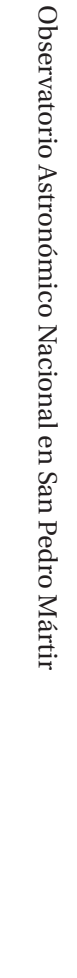 } & \multirow{33}{*}{ 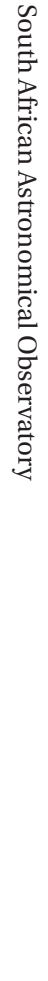 } & 5 \\
\hline 2 & Bisdee Tier Optical Astronomy Observatory & Indian Astronomical Observatory & & & \\
\hline 3 & Bisdee Tier Optical Astronomy Observatory & Assy-Turgen Observatory & & & $\hat{\xi}$ \\
\hline 4 & Bisdee Tier Optical Astronomy Observatory & Tien-Shan Observatory & & & $\frac{3}{0}$ \\
\hline 5 & Bisdee Tier Optical Astronomy Observatory & Pamir High-Mountain Observatory & & & $\stackrel{\Xi}{\Xi}$ \\
\hline 6 & Bisdee Tier Optical Astronomy Observatory & Sanglokh Observatory & & & के \\
\hline 7 & Bisdee Tier Optical Astronomy Observatory & Mount Dushak-Erekdag Observatory & & & $\stackrel{0}{0}$ \\
\hline 8 & Bisdee Tier Optical Astronomy Observatory & Maidanak Observatory & & & D \\
\hline 9 & Bisdee Tier Optical Astronomy Observatory & Roque de Los Muchachos Observatory & & & $\sum_{2}^{2}$ \\
\hline 10 & Bisdee Tier Optical Astronomy Observatory & Skinakas Observatory & & & $\stackrel{3}{0}$ \\
\hline 11 & Bisdee Tier Optical Astronomy Observatory & Tubitak National Observatory & & & 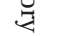 \\
\hline 12 & Siding Spring Observatory & Khurel Togoot Observatory & & & \\
\hline 13 & Siding Spring Observatory & Indian Astronomical Observatory & & & \\
\hline 14 & Siding Spring Observatory & Assy-Turgen Observatory & & & \\
\hline 15 & Siding Spring Observatory & Tien-Shan Observatory & & & \\
\hline 16 & Siding Spring Observatory & Pamir High-Mountain Observatory & & & \\
\hline 17 & Siding Spring Observatory & Sanglokh Observatory & & & \\
\hline 18 & Siding Spring Observatory & Mount Dushak-Erekdag Observatory & & & \\
\hline 19 & Siding Spring Observatory & Maidanak Observatory & & & \\
\hline 20 & Siding Spring Observatory & Roque de Los Muchachos Observatory & & & \\
\hline 21 & Siding Spring Observatory & Skinakas Observatory & & & \\
\hline 22 & Siding Spring Observatory & Tubitak National Observatory & & & \\
\hline 23 & Vintage Lane Observatory & Khurel Togoot Observatory & & & \\
\hline 24 & Vintage Lane Observatory & Indian Astronomical Observatory & & & \\
\hline 25 & Vintage Lane Observatory & Assy-Turgen Observatory & & & \\
\hline 26 & Vintage Lane Observatory & Tien-Shan Observatory & & & \\
\hline 27 & Vintage Lane Observatory & Pamir High-Mountain Observatory & & & \\
\hline 28 & Vintage Lane Observatory & Sanglokh Observatory & & & \\
\hline 29 & Vintage Lane Observatory & Mount Dushak-Erekdag Observatory & & & \\
\hline 30 & Vintage Lane Observatory & Maidanak Observatory & & & \\
\hline 31 & Vintage Lane Observatory & Roque de Los Muchachos Observatory & & & \\
\hline 32 & Vintage Lane Observatory & Skinakas Observatory & & & \\
\hline 33 & Vintage Lane Observatory & Tubitak National Observatory & & & \\
\hline
\end{tabular}


were predicted using the SGP4 orbit propagator. The simulation was performed with respect to the ten domestic satellites in connection with the 33 combinatorial cases, resulting in 330 visibility analysis diagrams as shown in Figs. 8-10.

In these figures, the horizontal axis represents the observationally visible time, while the vertical axis the observatories determined for the satellites. All the 33 cases showed the difference less than $1 \sigma$, but we found following differences by comparing the observatories having a similar visibility trend. Different from our expectation, a better result was found, not in the observatories that had a local superiority and thus had been included in all the combinatorial cases, but in the observatories that had not been included. Khurel Togoot Observatory showed the observationally visible time 1.2 times longer than that of Observatorio Astronómico Nacional en San Pedro Mártir in summer. Bisdee Tier Optical Astronomy Observatory and South African Astronomical Observatory showed a longer observationally visible time in winter than that of Las Campanas Observatory that was compared together (Fig. 8). In the third case where the communication, ocean and meteorological satellite-1 (COMS-1) was simulated, Assy-Turgen Observatory showed a far longer observationally visible time than that of other observatories (Fig. 9). In the 11st case, Korean institute of technology satellite-1 (KITSAT-1) seemed to have a similar visibility for the five determined observatories, but Tubitak National Observatory showed the observationally visible time 1.2 times longer than that of Astronómico Nacional en San Pedro Mártir or Las Campanas Observatory (Fig. 10). Hence, we finally determined the five observatories (Khurel Togoot, Assy-Turgen, Tubitak, Bisdee Tier and South Africa) as the optimal ground sites.

\section{FEASIBILITY ANALYSIS OF SERIES OBSERVA- TION BASED ON GROUND TRACK OF FICTITIOUS SATELLITES}

Series observation within 24 hours in the process of maintaining the ephemeris through optical observation may greatly help to maintain the ephemeris precision. To analyze the continuous feasibility through the ground track, we set up the Daeduk observatory (DO) and South African astronomical observatory (SAAO) at which series observation may be feasible on the basis of the latitude. Then, we set fictitious sites (FS), considering the series

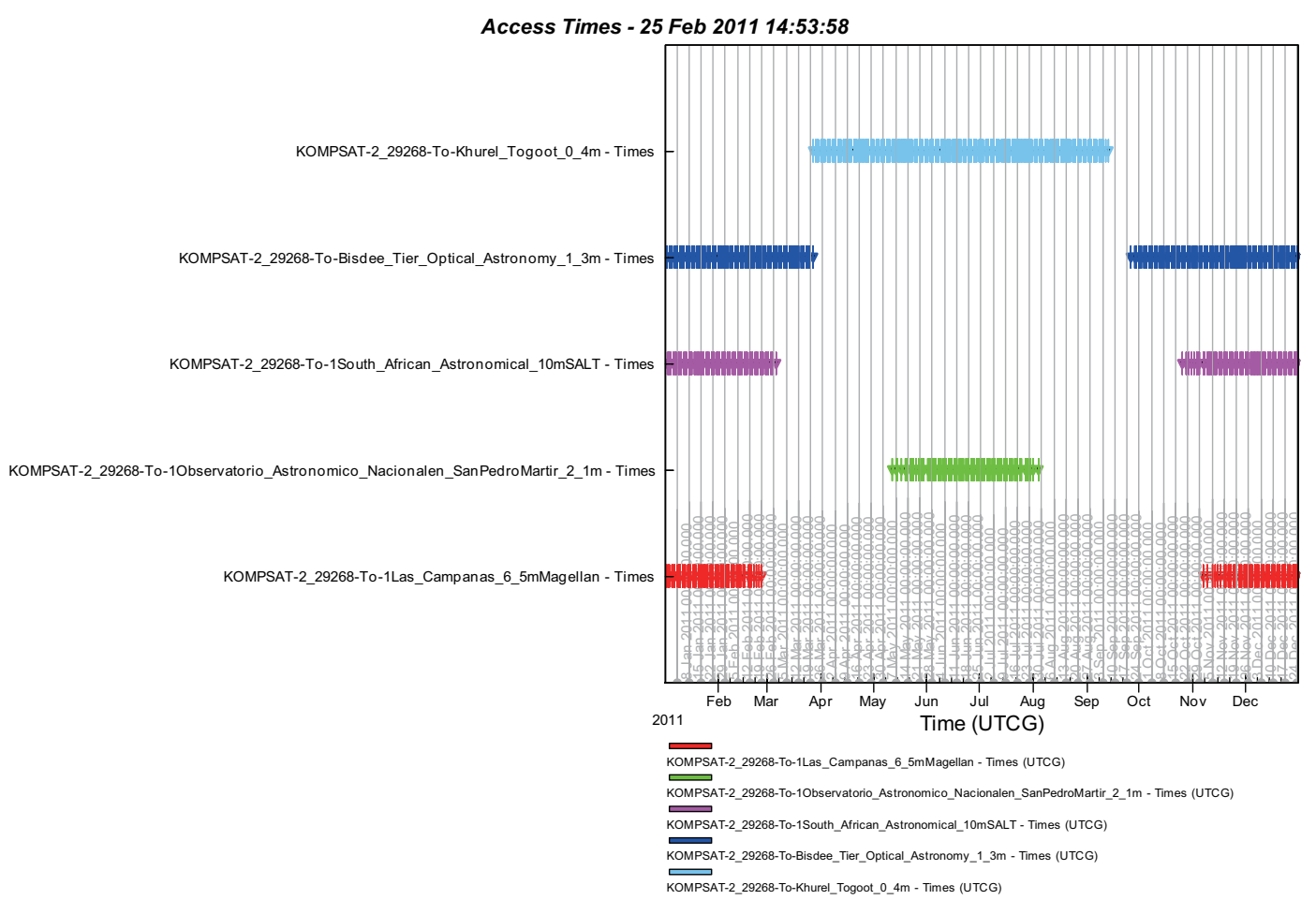

Fig. 8. Visibility duration of Korea multi-purpose satellite-2 (KOMPSAT-2) on selected 5 ground sites (1st case) is plotted in a chart, and the different color distinguish between sites. 


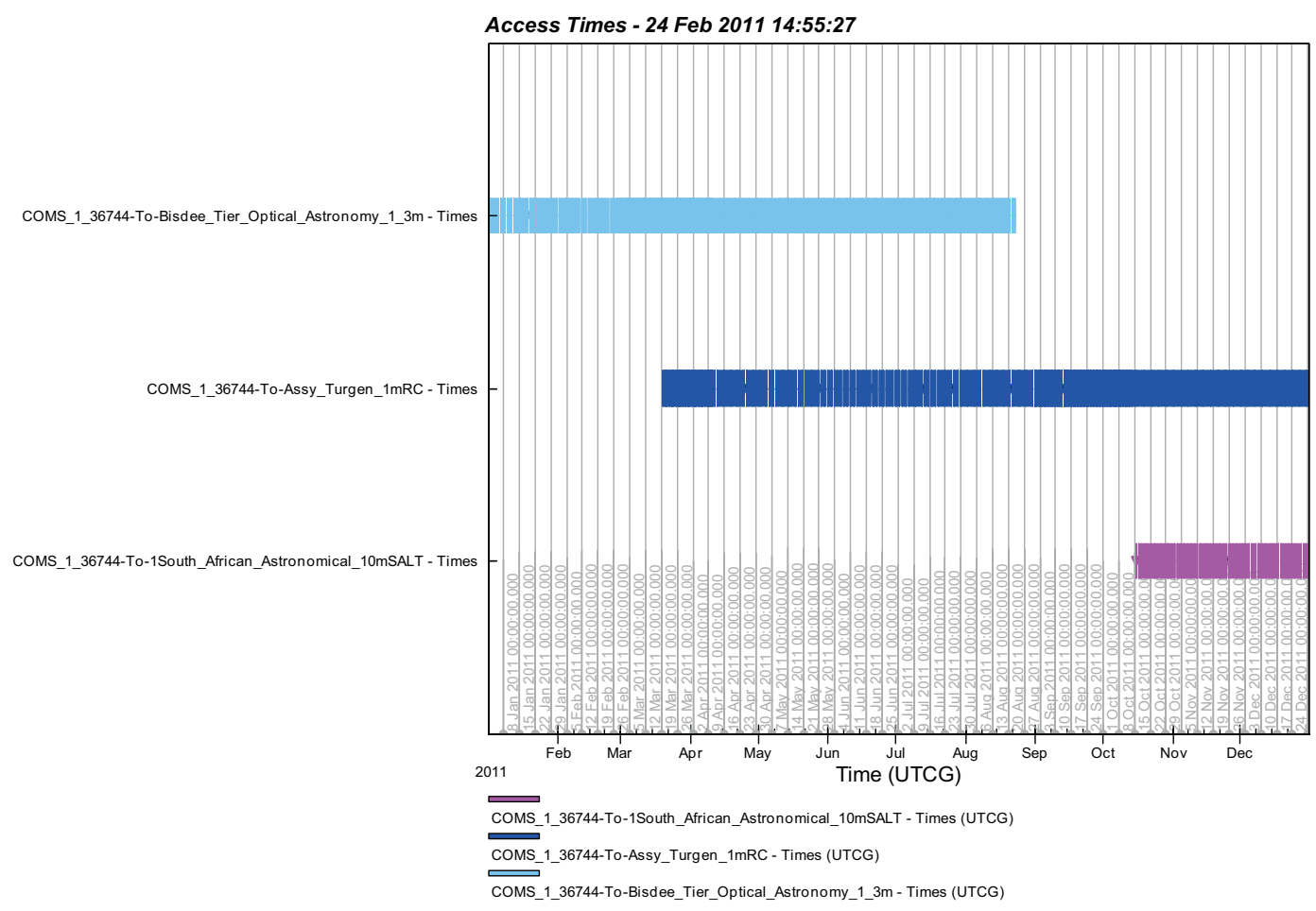

Fig. 9. Visibility duration of the communication, ocean and meteorological satellite-1 (COMS-1) on selected 5 ground sites (3rd case) is plotted in a chart, and the different color distinguish between sites.

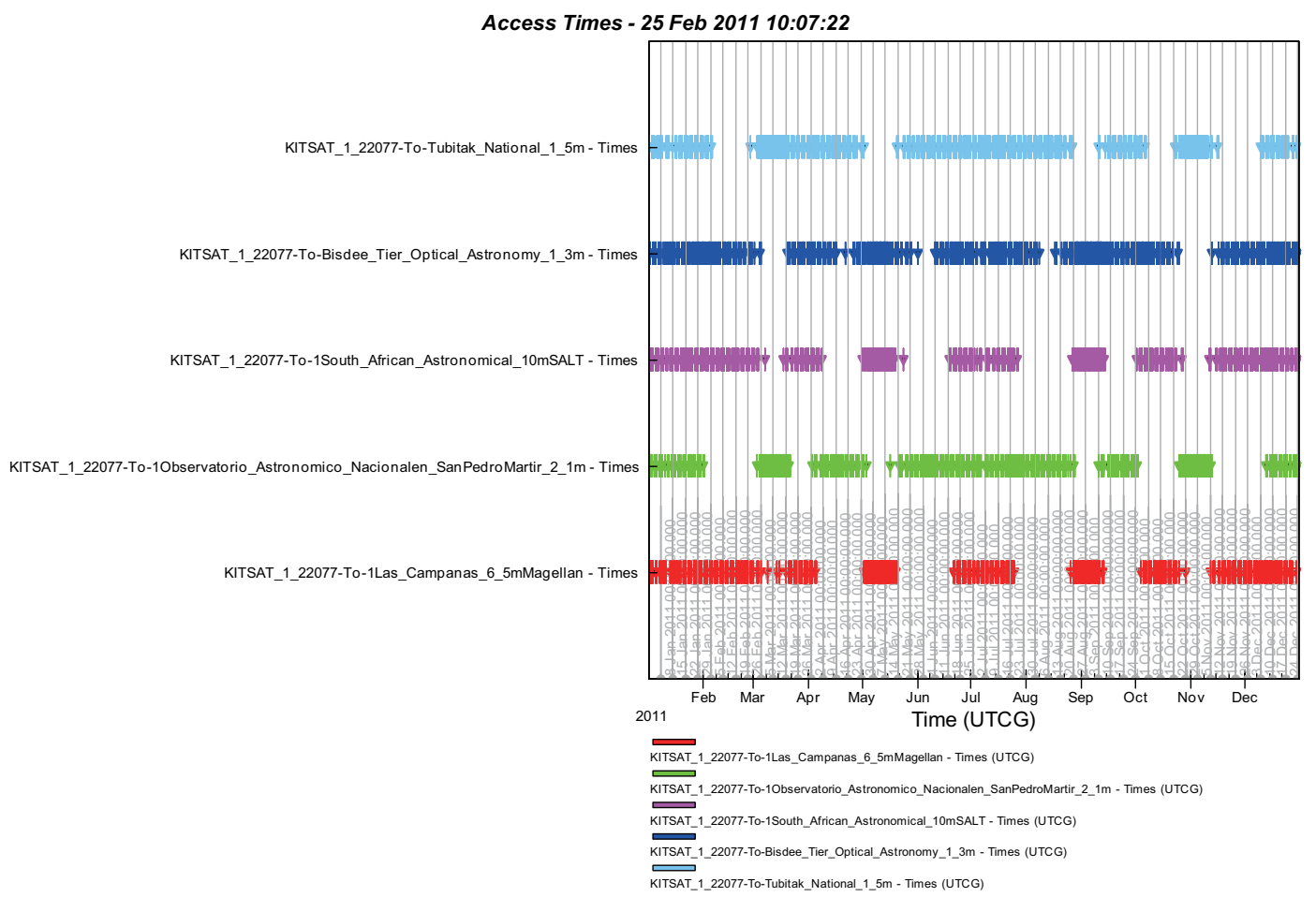

Fig. 10. Visibility duration of Korean institute of technology satellite-1 (KITSAT-1) on selected 5 ground sites (11th case) is plotted in a chart, and the different color distinguish between sites. 
observation feasibility with the DO to the full (Table 7). The simulation period was for one day and three days on each equinox and solstice (the spring equinox, summer solstice, autumnal equinox and winter solstice). The specifications of the subject satellites, five fictitious satellites for each orbital inclination as well as KOMPSAT-2, are presented in Table 8. KOMPSAT-2 was used as the reference to compare the fictitious satellites with an actual one. In the simulation, the SGP4 orbit propagator of which TLE is updated in real-time was used for KOMPSAT-2. Since the TLE had to be manually put in to the other fictitious satellites, without automatic TLE update, we employed the J4 Perturbation orbit propagator ${ }^{3}$ that allowed the orbit propagation from the initial input orbital elements. J4 Perturbation (second-order) propagator accounts for secular variations in the orbit elements due

${ }^{3} \mathrm{http}: / /$ www.stk.com/resources/help/online/stk/source/stk/vehsat orbitprop choose.htm [cited 2011 Feb 2] to Earth oblateness, which does not model atmospheric drag or solar or lunar gravitational forces.

The simulation result showed that the maximum number of times for series observation per day was one between DO and SAAO. The mean number of times for series observation per day between DO and the FSs was about one as shown in Table 9, although there was some exceptional cases when the maximum was three times in a day (orbital inclination 98 degree on the winter solstice). Here, 1 point represents the case where series observation was performed for one time, while 0 point represents the case where the observation was possible but not continuously. In the case of three-day interval simulation, the number of times for series observation between DO and FS was relatively greater on the winter solstice, and the number of times for observation was the greatest for the fictitious satellite whose orbit inclination was 99 degree, as shown in Table 10. Therefore, series observation is one factor to increase the precision when maintaining the

Table 7. Characteristics of chosen 2 ground sites and 1 fictitious ground site.

\begin{tabular}{lcccc}
\hline \multicolumn{1}{c}{ Proposed ground sites } & Latitude (deg) & Longitude (deg) & Elevation $(\mathbf{m})$ & Main telescope \\
\hline South African Astronomical Observatory & -32.378 & 20.8105 & 1,759 & $10 \mathrm{~m}$ SALT \\
Daeduk Observatory & 36.3214 & 127.42 & 0 & \\
Fictitious Site Observatory & 0 & -50 & 0 & \\
\hline
\end{tabular}

SALT: southern African large telescope.

Table 8. Specification of the 5 fictitious satellites and KOMPSAT-2.*

\begin{tabular}{lccccc}
\hline Satellite & Perigee $(\mathbf{k m})$ & Apogee $(\mathbf{k m})$ & Inclination $(\mathbf{d e g})$ & Period $(\mathbf{s e c})$ & Semi-major axis $(\mathbf{k m})$ \\
\hline Inc96 & 99.9428 & 99.9428 & 96 & $5,188.96$ & $6,478.08$ \\
Inc97 & 390.496 & 390.496 & 97 & $5,541.95$ & $6,768.63$ \\
Inc98 & 652.309 & 652.309 & 98 & $5,866.58$ & $7,030.45$ \\
Inc99 & 891.235 & 891.235 & 99 & $6,168.17$ & $7,269.37$ \\
Inc100 & 1111.42 & 1111.42 & 100 & $6,450.52$ & $7,489.55$ \\
KOMPSAT-2 & 656.3 & 680.9 & 98.1 & 5,916 & $7,066.9$ \\
\hline
\end{tabular}

KOMPSAT-2: Korea multi-purpose satellite-2.

"http://en.wikipedia.org/wiki/Arirang-2 [cited 2011 Feb 4]

Table 9. Series observation frequency during the day at equinoxes.

\begin{tabular}{lcccc}
\hline \multicolumn{1}{c}{ Satellite } & Vernal equinox & Summer solstice & Autumnal equinox & Winter solstice \\
\hline Inc100 (DO,FS) & 1 point & 1 point & 1 point & 2 points \\
Inc100 (DO,SAAO) & 1 point & 0 point & 0 point & 1 point \\
Inc99 (DO,FS) & 1 point & N/A & 2 points & 2 points \\
Inc99 (DO,SAAO) & 0 point & N/A & 0 point & 1 point \\
Inc98 (DO,FS) & $\mathrm{N} / \mathrm{A}$ & $\mathrm{N} / \mathrm{A}$ & 1 point & 3 points \\
Inc98 (DO,SAAO) & $\mathrm{N} / \mathrm{A}$ & $\mathrm{N} / \mathrm{A}$ & 0 point & 0 point \\
Inc97 (DO,FS) & 1 point & $\mathrm{N} / \mathrm{A}$ & 1 point & 2 points \\
Inc97 (DO,SAAO) & 0 point & $\mathrm{N} / \mathrm{A}$ & 0 point & point \\
Inc96 (DO,FS) & $\mathrm{N} / \mathrm{A}$ & $\mathrm{N} / \mathrm{A}$ & $\mathrm{N} / \mathrm{A}$ & N/A \\
Inc96 (DO,SAAO) & $\mathrm{N} / \mathrm{A}$ & $\mathrm{N} / \mathrm{A}$ & $\mathrm{N} / \mathrm{A}$ & N/A \\
KOMPSAT-2 (DO,FS) & $\mathrm{N} / \mathrm{A}$ & 1 & $\mathrm{~N} / \mathrm{A}$ & N/A \\
KOMPSAT-2 (DO,SAAO) & N/A & 0 &
\end{tabular}

KOMPSAT-2: Korea multi-purpose satellite-2, DO: Daeduk observatory, FS: fictitious sites, SAAO: South African astronomical observatory, N/A: not available. 
Table 10. Series observation frequency during 3 days at equinoxes.

\begin{tabular}{lcccc}
\hline \multicolumn{1}{c}{ Satellite } & Vernal equinox & Summer solstice & Autumnal equinox & Winter eolstice \\
\hline Inc96 (DO,FS) & N/A & N/A & N/A & 2 points \\
Inc97 (DO,FS) & 3 points & N/A & 2 points & 6 points \\
Inc98 (DO,FS) & 4 points & N/A & 4 points & 8 points \\
Inc99 (DO,FS) & 3 points & N/A & 6 points & 15 points \\
Inc100 (DO,FS) & 6 points & 2 points & 6 points & 10 points \\
KOMPSAT-2 (DO,FS) & N/A & 5 points & N/A & N/A \\
\hline
\end{tabular}

KOMPSAT-2: Korea multi-purpose satellite-2, DO: Daeduk observatory, FS: fictitious sites, N/A: not available.

ephemeris through optical observation. However, it does greatly affect the determination of the optimal ground sites, and is not appropriate as a requirement for enabling the ephemeris maintenance through optical observation, since its actual frequency is not high.

\section{EFFECTIVE VISIBILITY ANALYSIS OF DOMES- TIC SATELLITES IN ACTION AND IN PLANNING ON SELECTED 5 GROUND SITES}

The EV analysis was performed to verify whether or not the observation data sufficient to maintain the ephemeris could be acquired from the finally determined optimal ground sites.

\subsection{Definition of EV}

$\mathrm{EV}$ is defined as the percentage of the actual observationally visible time, assuming the number of observation points needed for the ephemeris maintenance for two weeks of satellite flying to be 600 and the length of the time when the 600 points are continuously visible to be $100 \%$ (Jo 2011). Eq. (1) is the equation to calculate $\mathrm{EV}$. The observationally visible time shorter than 60 seconds is excluded when calculating $0 V_{S U M}$.

$$
\mathrm{EV}[\%]=\frac{0 V_{S U M}[\mathrm{sec}]}{600[\mathrm{sec}]} \times 100[\%]
$$

where EV denotes effective visibility, EV the Total sum of observationally visible passing time over each site which is longer than 60 second per piece in two weeks.

\subsection{Analysis of the Observationally Visible Time Dur- ing Two Weeks in Each Season for the Domestic Satel- lites}

The observationally visible time during two weeks in each season was analyzed for the five optimal ground sites (Khurel Togoot Observatory, Assy-Turgen Observatory, Tubitak National Observatory, Bisdee Tier Optical Astronomy Observatory, and South African Astronomical Observatory) among the ground site candidates shown in Table 2. The simulation period was for two weeks from the first day to the 14th day of January, April, July and October in 2010. The subject satellites were nine domestic LEO satellites including KOMPSAT-3, KOMPSAT-3A and KOMPSAT- 5 that are to be launched. The specifications of the subject satellites are shown in Table 5. In the cases of the satellites to be launched, the simulation orbit was predicted using the J4 Perturbation orbit propagator to which nominal orbital elements are put in, while the SGP4 orbit propagator was used for other satellites. Fig. 11 shows the result. The horizontal axis in the figure represents the observationally visible time, and the vertical axis the individual satellites determined for each of the optimal ground sites.

With the observationally visible time obtained as the result of the simulation with respect to each satellite, $0 V_{\text {SUM }}$ was calculated by discarding the observation time shorter than 60 seconds and adding all the remaining time. If the $0 V_{\text {SUM }}$ resulted from the Eq. (1) is over $100 \%$, the observatory may be considered as the one where the optical observation data minimally required for the maintenance of the ephemeris can be acquired for two weeks.

\subsection{The EV Calculation Result}

Table 11 shows the EV calculation result for the optimal ground site for each domestic satellite. Firstly, it should be verified whether or not the $\mathrm{EV}$ meets the requirements of the optical observation data of the domestic satellites, including the satellites that will be operated in the future, needed for the maintenance of the ephemeris at the five determined optimal ground sites. Excluding KOMPSAT-3, KOMPSAT-3A and KOMPSAT-5 that are to be launched in the future, the observation data needed for the maintenance of the ephemeris are acquired averagely at three out of the five determined optimal ground sites 


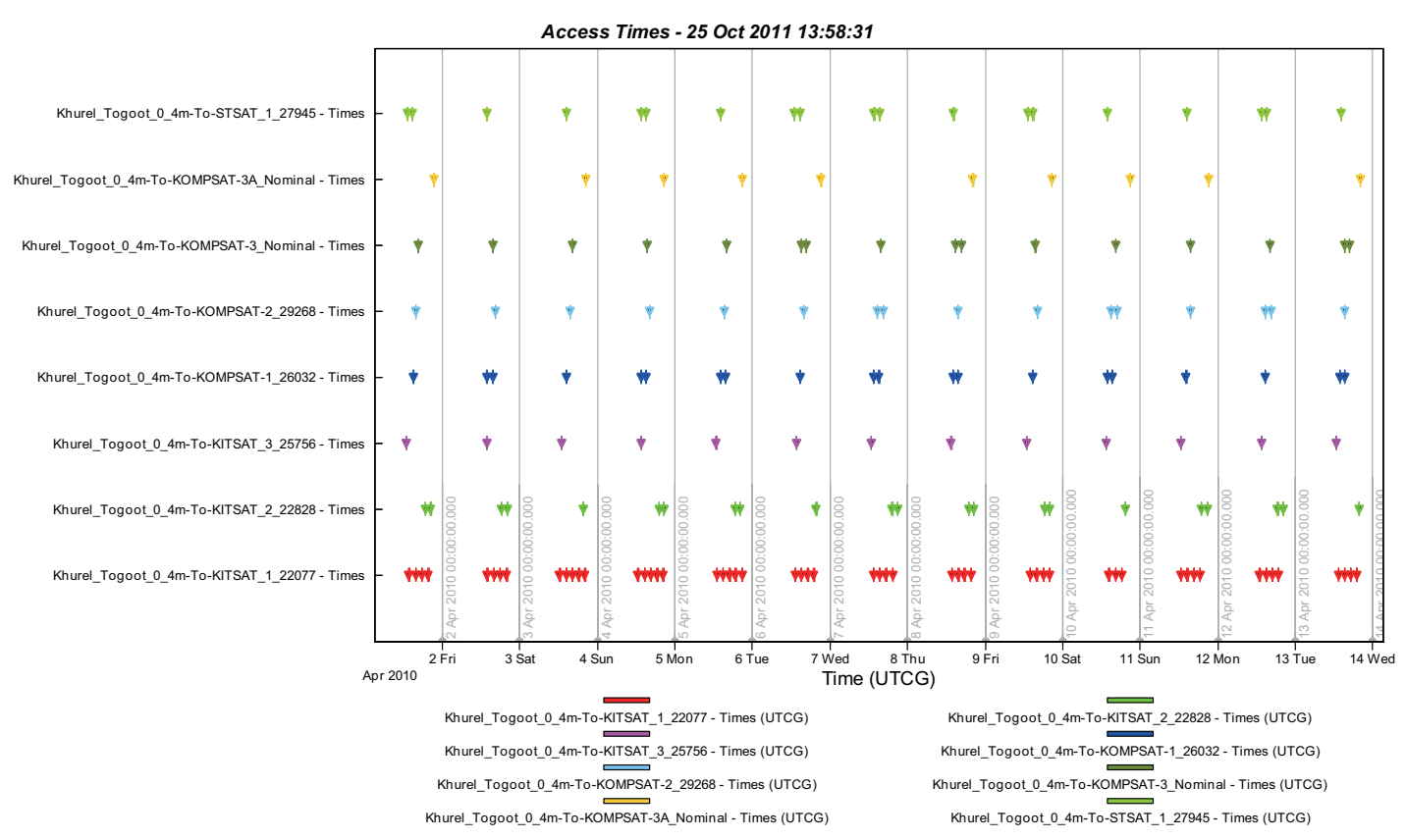

Fig. 11. Visibility duration of domestic satellites on Khurel Togoot Observatory (April) is plotted in a chart, and the different color distinguish between sites.

over a year. Particularly, Bisdee Tier Optical Astronomy Observatory has a great significance even among the optimal ground sites, since its overall $\mathrm{EV}$ is high and the observation is possible even when it is difficult at other ground sites. Among the SSO satellites, the observation in April and October may be difficult with KOMPSAT-3 and KOMPSAT-3A that are supposed to move along the ground track in a similar pattern with that of direct sun as well as KOMPSAT-5 that is supposed to move along the dawn-dusk orbit. Since the accurate orbital elements of the domestic satellites that are to be launched could not be identified, the orbit propagation was performed over an excessively long period of time depending on the nominal orbital elements in the simulation process, and thus the accuracy and reliability of the simulation results regarding the visibility were not high. For this reasons, even the simulation over a year with other candidates in addition to the five optimal ground sites would not enable to make right judgments. Therefore, the optical visibility over $80 \%$ could be obtained with respect to the domestic satellites at the selected optimal ground sites. The $\mathrm{EV}$ will be increased if the actual orbital elements of the domestic satellites are included in the future.

\section{SUMMARY}

To perform the optical surveillance and tracking of do- mestic satellites, we determined five optimal ground sites from 17 candidates, and investigated whether or not the observation data sufficient to maintain the ephemeris could be acquired from the finally determined optimal ground sites. Before determining the optimal ground site candidates, the optical observation limiting factors of the domestic SSO satellites were identified, and the result showed that the candidates on high latitudes (north latitude 25-34 degree or higher, south latitude 30-40 degree of higher) had an advantage for the observation of the SSO satellites. The LEO and MEO satellites were categorized according to the orbit inclination and the visibility was compared with each other. The result showed that the visibility and observation frequency were independent upon the orbital elements including orbit inclination, and the difference was less than $1 \sigma$ among the optimal ground site candidates. Thus, we found that it is more important to analyze the visibility at the optimal ground sites for the domestic satellites and the satellites to be launched in the country than analyzing any other factors. As a result, five ground sites (Khurel Togoot, Assy-Turgen, Tubitak, Bisdee Tier and South Africa) were finally determined. The series observation feasibility at two or more optimal ground sites, but the actual frequency was low. Thus, the series observation feasibility was not appropriate as a requirement for ephemeris maintenance. The EV was analyzed for the five determined optimal ground sites to verify whether or not the observation data suffi- 
Table 11. Effective visibility of observation site candidates for first session of January, April, July, October.

\begin{tabular}{|c|c|c|c|c|c|c|c|}
\hline Satellite & $\begin{array}{c}\text { SAAO } \\
(\%)\end{array}$ & $\begin{array}{c}\text { Tubitak } \\
(\%)\end{array}$ & $\begin{array}{c}\text { Assy-Turgen } \\
(\%)\end{array}$ & $\begin{array}{c}\text { Khurel } \\
\text { Togoot }(\%)\end{array}$ & $\begin{array}{c}\text { Bisdee-Tier } \\
(\%)\end{array}$ & $\begin{array}{c}\text { Observable } \\
\text { sites }\end{array}$ & Month \\
\hline STSAT-1 & $\begin{array}{r}696 \\
\text { N/A } \\
\text { N/A } \\
496\end{array}$ & $\begin{array}{r}\text { N/A } \\
53 \\
781 \\
\text { N/A }\end{array}$ & $\begin{array}{r}\text { N/A } \\
348 \\
617 \\
\text { N/A }\end{array}$ & $\begin{array}{r}\text { N/A } \\
639 \\
469 \\
\text { N/A }\end{array}$ & $\begin{array}{r}303 \\
184 \\
\text { N/A } \\
889\end{array}$ & $\begin{array}{l}2 \\
4 \\
3 \\
2\end{array}$ & $\begin{array}{r}1 \\
4 \\
7 \\
10\end{array}$ \\
\hline KITSAT-1 & $\begin{array}{r}1373 \\
1417 \\
1182 \\
44\end{array}$ & $\begin{array}{r}595 \\
1399 \\
2147 \\
1249\end{array}$ & $\begin{array}{l}1029 \\
2324 \\
2580 \\
1648\end{array}$ & $\begin{array}{l}1665 \\
3810 \\
3292 \\
1857\end{array}$ & $\begin{array}{l}2505 \\
1455 \\
1612 \\
1031\end{array}$ & $\begin{array}{l}5 \\
5 \\
5 \\
5\end{array}$ & $\begin{array}{r}1 \\
4 \\
7 \\
10\end{array}$ \\
\hline KITSAT-2 & $\begin{array}{l}394 \\
\text { N/A } \\
\text { N/A } \\
\text { N/A }\end{array}$ & $\begin{array}{r}\text { N/A } \\
152 \\
793 \\
\text { N/A }\end{array}$ & $\begin{array}{r}\text { N/A } \\
538 \\
953 \\
\text { N/E }\end{array}$ & $\begin{array}{r}\text { N/A } \\
876 \\
705 \\
122\end{array}$ & $\begin{array}{r}984 \\
\text { N/A } \\
\text { N/A } \\
23\end{array}$ & $\begin{array}{l}2 \\
3 \\
3 \\
2\end{array}$ & $\begin{array}{r}1 \\
4 \\
7 \\
10\end{array}$ \\
\hline KITSAT-3 & $\begin{array}{c}\text { N/A } \\
780 \\
852 \\
764\end{array}$ & $\begin{array}{r}555 \\
667 \\
339 \\
\text { N/A }\end{array}$ & $\begin{array}{r}520 \\
730 \\
159 \\
\text { N/E }\end{array}$ & $\begin{array}{r}796 \\
758 \\
117 \\
52\end{array}$ & $\begin{array}{r}\text { N/A } \\
636 \\
1029 \\
624\end{array}$ & $\begin{array}{l}3 \\
5 \\
5 \\
3\end{array}$ & $\begin{array}{r}1 \\
4 \\
7 \\
10\end{array}$ \\
\hline KOMPSAT-1 & $\begin{array}{r}729 \\
\text { N/A } \\
\text { N/A } \\
207\end{array}$ & $\begin{array}{l}\text { N/A } \\
\text { N/E } \\
803 \\
\text { N/A }\end{array}$ & $\begin{array}{r}\text { N/A } \\
128 \\
758 \\
\text { N/A }\end{array}$ & $\begin{array}{r}\text { N/A } \\
412 \\
594 \\
\text { N/A }\end{array}$ & $\begin{array}{r}507 \\
12 \\
\text { N/A } \\
742\end{array}$ & $\begin{array}{l}2 \\
3 \\
3 \\
2\end{array}$ & $\begin{array}{r}1 \\
4 \\
7 \\
10\end{array}$ \\
\hline KOMPSAT-2 & $\begin{array}{r}377 \\
\text { N/A } \\
\text { N/A } \\
\text { N/A }\end{array}$ & $\begin{array}{l}\text { N/A } \\
\text { N/A } \\
436 \\
\text { N/A }\end{array}$ & $\begin{array}{r}\text { N/A } \\
\text { N/E } \\
778 \\
\text { N/A }\end{array}$ & $\begin{array}{r}\text { N/A } \\
119 \\
996 \\
\text { N/A }\end{array}$ & $\begin{array}{c}854 \\
\text { N/A } \\
\text { N/A } \\
165\end{array}$ & $\begin{array}{l}2 \\
1 \\
3 \\
1\end{array}$ & $\begin{array}{r}1 \\
4 \\
7 \\
10\end{array}$ \\
\hline KOMPSAT-5 & $\begin{array}{l}\text { N/A } \\
\text { N/A } \\
\text { N/A } \\
\text { N/A }\end{array}$ & $\begin{array}{l}\text { N/A } \\
\text { N/A } \\
\text { N/E } \\
\text { N/A }\end{array}$ & $\begin{array}{c}\text { N/A } \\
\text { N/A } \\
261 \\
\text { N/A }\end{array}$ & $\begin{array}{c}\text { N/A } \\
\text { N/A } \\
498 \\
\text { N/A }\end{array}$ & $\begin{array}{l}289 \\
\text { N/A } \\
\text { N/A } \\
\text { N/A }\end{array}$ & $\begin{array}{l}1 \\
0 \\
2 \\
0\end{array}$ & $\begin{array}{r}1 \\
4 \\
7 \\
10\end{array}$ \\
\hline KOMPSAT-3 & $\begin{array}{r}247 \\
\text { N/A } \\
472 \\
\text { N/A }\end{array}$ & $\begin{array}{r}540 \\
\text { N/A } \\
225 \\
\text { N/A }\end{array}$ & $\begin{array}{r}657 \\
91 \\
99 \\
\text { N/A }\end{array}$ & $\begin{array}{r}822 \\
353 \\
24 \\
\text { N/A }\end{array}$ & $\begin{array}{r}126 \\
\text { N/A } \\
544 \\
10\end{array}$ & $\begin{array}{l}5 \\
2 \\
5 \\
1\end{array}$ & $\begin{array}{r}1 \\
4 \\
7 \\
10\end{array}$ \\
\hline KOMPSAT-3A & $\begin{array}{r}\text { N/A } \\
\text { N/A } \\
653 \\
\text { N/A }\end{array}$ & $\begin{array}{l}513 \\
\text { N/A } \\
\text { N/A } \\
\text { N/A }\end{array}$ & $\begin{array}{l}505 \\
\text { N/A } \\
\text { N/A } \\
\text { N/A }\end{array}$ & $\begin{array}{l}625 \\
\text { N/E } \\
\text { N/A } \\
\text { N/A }\end{array}$ & $\begin{array}{c}\text { N/A } \\
\text { N/A } \\
651 \\
\text { N/A }\end{array}$ & $\begin{array}{l}3 \\
0 \\
2 \\
0\end{array}$ & $\begin{array}{r}1 \\
4 \\
7 \\
10\end{array}$ \\
\hline
\end{tabular}

SAAO: South African astronomical observatory, STSAT-1: science and technology satellite-1, KITSAT: Korean institute of technology satellite, KOMPSAT: Korea multi-purpose satellite, N/A: not available, N/E: not enough access time.

cient for the satellites to maintain the ephemeris could be acquired. The result showed that the observation data sufficient to maintain the ephemeris could be acquired at all the five determined optimal ground sites and that the EV was higher than $80 \%$ for the domestic satellites. When considering the sites for the optimal ground sites in the process of establishing the optical telescope system for space object surveillance and tracking, the five sites that were found in this study to have high visibility and EV may be selected preferentially, if other conditions are the same including the basic infrastructure. Additionally, the optical observation system could be established on the basis of the assumption that the determined optimal ground sites are located at the most advantageous positions for the optical observation of the domestic satellites and that the data acquired from the observation are sufficient to maintain the ephemeris.

\section{ACKNOWLEDGEMENTS}

This work was supported by the Korea Astronomy and Space Science Institute through the project "Development of Electro-optic Space Surveillance System" funded by Korea Research Council of Fundamental Science \& Technology.

\section{REFERENCES}

Jo JH, 2011, private communication.

Kim C-H, Shin J-S, Park P-H, Kim T-H, Lee B-S, et al., A Study on the Computer Programs for the Tracking and Position Predictions of Artificial Satellites, Ministry of Science and Technology, MOST/N8613, 39-63 (1987).

Kim J-H, OWL-Net System Requirement Analysis Document, Observation Feasibility Analysis of Dawn-dusk satel- 
lites, OWL-TR-SYSTEM-110405-01-KJH (2011a).

Kim J-H, OWL-Net System Requirement Analysis Document, Visibility Analysis of Satellites on Selected Ground Sites, OWL-TR-SYSTEM-110405-08-KJH (2011b).

King-Hele D, Observing Earth Satellites (Macmillian, London, 1983), 1-184.
Moon H-K, OWL-Net System Requirement Analysis Document, Documentary Survey of Overseas Observational Sites, OWL-TN-ST-110207-01-MHK (2011).

Pearlman MR, Degnan JJ, Bosworth JM, The international laser ranging service, AdSpR, 30, 135-143 (2002). http:// dx.doi.org/10.1016/S0273-1177(02)00277-6 